\title{
Risk Factors When Implementing ERP Systems in Small Companies
}

\author{
Ann Svensson * ${ }^{(D)}$ and Alexander Thoss
}

check for

updates

Citation: Svensson, A.; Thoss, A. Risk Factors When Implementing ERP Systems in Small Companies. Information 2021, 12, 478. https:// doi.org/10.3390/info12110478

Academic Editor: Shahram Latifi

Received: 15 October 2021

Accepted: 15 November 2021

Published: 19 November 2021

Publisher's Note: MDPI stays neutral with regard to jurisdictional claims in published maps and institutional affiliations.

Copyright: (c) 2021 by the authors. Licensee MDPI, Basel, Switzerland. This article is an open access article distributed under the terms and conditions of the Creative Commons Attribution (CC BY) license (https:/ / creativecommons.org/licenses/by/ $4.0 /)$.
School of Business, Economics and IT, University West, 46186 Trollhättan, Sweden; alexander.thooss@gmail.com * Correspondence: ann.svensson@hv.se

\begin{abstract}
Implementation of enterprise resource planning (ERP) systems often aims to improve the companies' processes in order to gain competitive advantage on the market. Especially, small companies need to integrate systems with suppliers and customers; hence, ERP systems often become a requirement. ERP system implementation processes in small enterprises contain several risk factors. Research has concluded that ERP implementation projects fail to a relatively high degree. Small companies are found to be constrained by limited resources, limited IS (information systems) knowledge and lack of IT expertise in ERP implementation. There are relatively few empirical research studies on implementing ERP systems in small enterprises and there is a large gap in research that could guide managers of small companies. This paper is based on a case study of three small enterprises that are planning to implement ERP systems that support their business processes. The aim of the paper is to identify the risk factors that can arise when implementing ERP systems in small enterprises. The analysis shows that an ERP system is a good solution to avoid using many different, separate systems in parallel. However, the study shows that it is challenging to integrate all systems used by suppliers and customers. An ERP system can include all information in one system and all information can also easily be accessed within that system. However, the implementation could be a demanding process as it requires engagement from all involved people, especially the managers of the companies.
\end{abstract}

Keywords: ERP systems; implementation; risk factors; small companies

\section{Introduction}

The implementation of enterprise resource planning (ERP) systems often aims to improve the companies' processes in order to gain competitive success on the market. Especially, small companies need to integrate their systems with suppliers and customers and, therefore, ERP systems often become a requirement [1]. However, ERP systems implementation is a risky endeavor for both large, medium and small enterprises, as a large number of implementation project have failed in recent years [2]. For example, only $33 \%$ of all ERP systems implementations are claimed to have been successful and $90 \%$ have run out of budget [3]. Research has also concluded that between $70 \%$ and $85 \%$ of ERP implementation projects fail due to overruns of cost or schedule, or that failures are due to the overall fit to the enterprise's processes [2,4,5]. Implementing an ERP system is complex and can, thus, imply some risks for all companies, especially small companies without specific knowledge and experience in ERP implementation. Implementing a new ERP system requires both knowledge, time and resources, and shortage of any of these factors is associated with some risk [6]. Large enterprises can utilize large budgets and pools of skilled resources for an ERP implementation, which is not the case for small and medium-sized enterprises (SMEs). Many more characteristics distinguish SMEs from large enterprises, such as ownership type, structure, culture and market [7].

The enterprises would create success factors and they want to integrate activities to make the business processes more efficient [3]. However, the majority of research that 
has been conducted regarding critical success factors in implementing ERP systems have showed that it is challenging for SMEs to implement mitigation strategies for successful ERP systems implementations. The implementation process is costly. Such an implementation process involves all roles in an enterprise and affects all established processes and results in a transformation of the enterprise's work procedures [8]. Many companies have started to realize the implications and risks associated with the implementation process, especially large enterprises. However, too many companies still embark on the implementation process without knowing what to expect or how to manage the implementation process. This is the situation in many small companies, as they are constrained by limited resources, limited IS knowledge and lack of IT expertise [2,9]. Thus, small enterprises are more fragile, than large enterprises [2]. Goldston [2] also highlights more factors that are especially crucial for small enterprises, such as proper system implementation strategy, clearly defined scope of the implementation procedure, proper project planning and minimal customization of the system selected for implementation. Small enterprises often have limited time and budget for customization of systems. Much research has been conducted in large companies on guiding managers about important factors to consider when implementing ERP systems, but there is a large gap in research that could guide managers of small companies on these matters [1]. Kiran and Reddy [10] also claim that much research is needed to ascertain facts and make recommendations for faster implementation of ERP systems in SMEs. In recent years, the technical paradigm has changed, as cloud computing has become more usual, which also calls for a revisit of the situation in implementing ERP systems in small enterprises. To make the enterprises more prepared for the ERP implementation process and avoid mistakes, it is important to understand what kind of risk factors can occur in such situations [6]. Thus, this paper will consider important and relevant risk factors within small companies and extends the previous study conducted by Johansson and Svensson [11].

This paper is based on a case study including three small private companies. The companies plan to implement ERP systems to support their operations and become more efficient. The aim of the paper is to analyze which risk factors can emerge when implementing ERP systems in small enterprises. That implies that this paper will pay attention to the challenges and consequences associated with the ERP systems implementation process.

The paper is organized in five parts. First, the theoretical background presents the theoretical lens from which the case study research is conducted. The methodology is presented in the next section, followed by the empirical cases and the results. Finally, the findings are analyzed and discussed and the conclusions are presented.

\section{Materials and Methods}

\subsection{Theoretical Background}

This section describes objectives for ERP systems implementations and relations to known risk factors in enterprises.

\subsubsection{ERP Systems and Implementation}

ERP systems are viewed as key enablers of the digital transformation of an organization's business, in particular for the sustainability of SMEs in the competitive environments that businesses face today [12]. Enterprises, not the least small enterprises, need efficient and effective information systems like ERP systems to compete in today's complex and fast market economy. An ERP system can be defined as a software developed to manage and handle the information within a company. ERP systems originate in manufacturing and planning systems, but their use has expanded to all other "back-office" functions in enterprises. The key objective of implementing ERP systems is to decrease operation costs in enterprises, by improving the operating efficiency and business processes [13]. Through this computer-based information system, the enterprise can gather resources and information including all parts of the organization and different modules can be used for different services, as human resources, financial resources, supply chain, customer 
relationship management, as well as material and production planning. The integrated modules allow the different functions in an enterprise to communicate with each other through information sharing. Thus, ERP systems facilitate cooperation and interactions between all units and processes within an enterprise, in standardized processes based on business best practices. ERP systems are designed to seamlessly integrate information in order to better plan and respond to needs in the enterprise and its management and services. Often, ERP systems are considered as the information backbone of the enterprise's core business processes [14]. Those systems are designed to facilitate the administration and optimization of internal business processes across an enterprise and have become the competitive tool for many large enterprises [15]. ERP systems use a single database. However, the implementation and deployment of ERP systems can be very risky and costly, despite the many benefits [16]. In fact, implementation projects of ERP systems have high failure rates $[2,16]$.

ERP systems are considered to be relatively easy to customize to specific companies' own needs and can, thus, be adapted to activities and processes in small enterprises [17]. ERP systems have a process-oriented approach and provide a smooth flow of information between different sections of an enterprise. ERP systems often exist as a standard solution based on information technology, consisting of a database and a standardized architecture that could be used by many companies. The needs of the enterprise are important to examine carefully and match with the functions in each specific ERP system [18]. The reason for an enterprise to invest in an ERP system is, thus, to achieve better performance of its business processes [19]. There are many different ERP systems provided by vendors on the market. The vendors can offer a customized ERP system based on the needs of the enterprise. To analyze and compare different ERP systems can be quite time consuming and very costly for a small enterprise [8]. Each implementation project is unique and it is very difficult to predict the risks for each individual enterprise. There is an interplay among many factors that could pose a risk, regardless of how prepared the company is [18]. The ERP system implementation should be conducted as efficiently as possible and the ERP system should result in more efficient activities in the enterprise.

The implementation process has thorough effects in an enterprise, not only related to the operative technical environment. The strategic effects in the enterprise will be even more perceptible [8]. Implementation of ERP systems requires engagement from senior and executive management, as well as from all people involved, as it causes organizational changes and changes the way people work [13]. SMEs often have limited time, resources, skills and budgets for the implementation of ERP systems and the implementation process generally requires such input. In addition, SMEs often lack IT infrastructure and the latest technology, and the quality of available business data could be relatively low [12].

\subsubsection{Risk Factors Associated with Implementation}

Some important risk factors associated with implementation of ERP systems are mentioned in the literature. Such risk factors are described as technical problems, organizational change, lack of management support, project strategy, training, resistance and project management [20-22]. Critical success factors in SMEs, on the other hand, are related to organizational factors and top management support [10]. Taghipour et al. [16] suggest a risk structure that considers different types of risks, such as environmental risks, project management risks, technical and technological risks, as well as organizational and structural risks. Additional risk factors are mentioned by Garg and Garg [15], such as poor consultant effectiveness, ERP software misfit, unrealistic expectations from top management and over-reliance on heavy customization, among other risk factors. However, research has revealed that most risk factors are not associated with technology, such as issues associated with compatibility, technological complexity and standardization. Instead, most risk factors are related to organizations and humans. Such important risk factors include resistance to change, organizational culture and existing business processes [13]. 
An ERP system is based on a standardized software that could be suitable for all enterprises. The ERP system has to be adapted to the processes conducted in the organization, which requires changes in the business processes in order to make them more efficient. Issues related to customization of ERP systems and business process reengineering are considered as the main barriers for the implementation process in small companies [12]. This implies changes in the established business processes within an organization in accordance with the functionality of the specific ERP system. ERP systems are standardized to a certain degree and intend to support organizations in a pre-defined way. Such systems can often lead to increased efficiency and performance within an organization. However, if weak and inefficient routines and processes continue to be supported with an ERP system in an enterprise, it will not result in more efficient operations. Then, the system can consolidate old and inefficient routines [23]. However, implementation of an integrated and standardized ERP system can lead to time delays and have a very negative impact on the small enterprise's processes. Small enterprises need to be flexible and modify the existing processes and realign the workflow for better adaptability with the ERP system [20].

Within the implementation process, organizational change often takes place. This implies that the enterprise has to analyze its existing work tasks, activities and processes $[18,24]$. To have the support from the manager in the company is one of the most critical success factors in the implementation of an ERP system. However, since an implementation often has great impacts within the enterprise, it is important that not only the manager is responsible for the adoption of the ERP system. According to Ganly [25], it is important to also involve the employees in order to increase engagement in all levels. If this is not the case, problems due to poor adoption will arise, as the use of existing systems and routines will be mixed by the use of the ERP system and the performance of business processes will be ineffective.

Technical challenges can emerge when a new ERP system is implemented to support the operations in an enterprise. Since companies often have a set of existing systems, it is very important to study the needs of the existing systems and if integration is possible, when implementing a new system [26]. Moreover, suppliers and customers also use different systems that need to be integrated into the ERP system. Different technical challenges are identified in the literature [10]. Customization, functional complexity in ERP software and complexity in application management are some of the reported challenges. Challenges such as lack of support from vendors, multi-vendor complexity related to software, hardware and/or consultants, complex integrations with legacy systems, security concerns, insufficient IT infrastructure and problems associated with interconnecting functional systems could further complicate the implementation of ERP systems in small enterprises.

It is important to create good conditions for the project planning, as the implementation of an ERP system is a risky and complex project. Clear goals in order to reach success are also important to define. Raj and Seetharaman [27] have demonstrated that failures in the planning process can imply large risks for the implementation in small enterprises. Decreasing the budget for the implementation process often results in unsuccessful projects; therefore, it is highly critical to assign project costs in the budget [25]. However, small enterprises often have quite strict budget constraints. An effective project management strategy guarantees that the implementation of the ERP system is conducted as planned. Good project management creates good communication and interaction in the project management team, where members from the enterprise, the vendor and, if appropriate, also from the consultant firm participate. Less good project management could result in negative impacts on the users' moral attitudes and could imply negative attitudes to the implemented ERP system [25].

Education and training are important in the implementation process of a new ERP system, in order to avoid problems. Requirement of training is also reported as one of the main barriers to implementation of ERP systems [12]. Lack of training often leads to unsuccessful implementation [25]. Often, only a few users are trained and they in turn are supposed to educate the rest of the employees within the organization [25]. This approach 
increases the risk of unsuccessful implementation, because poorly educated users can develop negative attitudes towards the ERP system and make it harder to take advantage of the new ERP system. To implement a new ERP system is a risky process that is not only associated with advantages; there is also a risk that the users will resist the implementation. The reasons users can be resistant can be related to changes of established routines within the enterprise, changes that, e.g., result in a higher workload for the employees in the implementation process, which could be perceived as negative [28,29]. The management needs to consider the advantages of the ERP system and clearly define the aim with the implementation and communicate it to everyone involved. The goal could be full acceptance of the changes by the employees, as the intention of the implementation of the ERP system is to make the work more efficient and smoother. The management should also ensure that the implementation does not have any negative impacts on the daily work [30].

\subsection{Research Method}

This study was conducted as a case study, by using a qualitative approach $[11,31,32]$. This approach is commonly used in studies of implementation and use of information systems in organizations. The research is influenced by the interpretive perspective as it focuses on understanding complexity in the context and in the process of implementing ERP systems in small enterprises [33]. The case study produces context-dependent knowledge and experience from the implementation processes $[11,34]$. Especially, the processes related to the ERP implementation were studied.

In order to get deep insights into the different organizational aspects within the processes in the enterprises, the data collection focused on different ways of gathering information. The primary data sources were semi-structured interviews, studies of internal documents, observations, informal discussions and participation in meetings in the enterprises. Using those data, we were able to obtain both retrospective and real-time data from the people experiencing the phenomena of interest $[11,35]$. When studying the work conducted at the workplaces, we had opportunities to see what people do, hear them explain their work and get insights into their routines, dilemmas, frustrations and relationships at their daily work $[11,36]$. Questions were asked by the researchers and also when questions appeared during the observations [37].

We analyzed the implementation process and the needs, as well as the challenges associated with implementing ERP systems in the enterprises [11]. The study also includes the analysis of the customization of the ERP systems in order to value the prospective effects in the enterprises. One of the cases is related to a customization of an ERP system intended to be configured to support the inventory management, the invoicing and the administration of production orders, together with suppliers and customers resources management, described in Johansson and Svensson [11]. The data collection and analysis overlapped in iterations to reach closure with saturated data. The analysis took into account the routines and processes at the enterprises and also gives suggestions to the enterprises on how to make the routines and processes more aligned with the implementations of the ERP systems.

Thematic analysis was used to find patterns and themes related to the implementation processes [38]. Different themes were found in the empirically collected data. The themes are related to the aim of the paper and to the theoretical background in order to analyze the empirical data. Thus, we crystallized four different themes; need for ERP systems, technical challenges, the performance of projects and the importance of training.

\subsection{The Empirical Cases}

The case study was conducted at three different small enterprises in the western part of Sweden. The first enterprise is a recruitment agency whose business concept is to recruit unemployed students. The company then sells consultants (working students), to other companies that need consultants. The company does not have any ERP system today, as they work mostly manually with all its processes. However, MS Excel is used for time 
reports and salaries. They have bought a system for the invoicing, Visma Avendo, as a cloud service and a system for bookkeeping. Moreover, they use Google Drive. Now, the management is planning to implement an ERP system to support and make the activities more efficient in the company, both for the employees and for the consultants. The company has five employees at the moment.

The second company is a software developing enterprise with six employees. Separate systems are used for invoicing and bookkeeping. Resource management with regard to suppliers and customers is conducted manually. Google Drive and Slack are used for collaborating internally as well as externally. The enterprise has relatively few customers to this date but is planning to expand by selling its application and is therefore now recruiting more sellers.

The third company is a small enterprise in the transportation sector, a cargo enterprise. This company has about ten employees and about ten suppliers and customers, respectively. All administration at the office is conducted manually, except for a bookkeeping application. Paper-based forms are used to keep track of transportations by different drivers. The salary and invoicing systems are manual and based on paper forms. The different customers use different ERP systems and it is possible for this company to access those internet-based systems with usernames and passwords.

\section{Results}

This section presents the four themes from the case study: need for ERP systems, technical challenges, projects' performance and the importance of training.

\subsection{Need for ERP Systems}

The recruitment agency considers that their work processes should be redefined and that they need a new ERP system to operate more efficiently. Today, the company has different systems and data storage solutions, as well as manual processes. By implementing one ERP system for all the processes in the company, there is an opportunity to collect all data in one system. The management of the company is aware that the implementation of the ERP system will result in large costs. There will also be costs associated with having the employees learn the system. The enterprise will be less efficient during the implementation period and the manager needs to plan for that period in relation to the workload.

The software developing enterprise is using an internet-based bookkeeping and billing system. The enterprise does not have so many customers yet, but it is developing its business to include several new customers at the time when the enterprise is studied. The plan is to recruit more sellers. The enterprise then needs to keep track of its prospects and offers and get information on the percentage of completed transactions in relation to prospects and offers. To do that, it could be suitable for this enterprise to use a customer relationship management (CRM) system, also as a prognostic tool. While the business processes related to the customers are conducted manually right now, the enterprise is planning to implement a suitable CRM system in the near future. When the enterprise has recruited more customers, an ERP system would be an alternative to the manual processes conducted today. This enterprise has costs for storing data in the cloud and the expenses for this type of ERP system are quite high. However, for the internal communication Google Drive and Slack are used, considered as quite inexpensive systems.

The cargo enterprise has a system for bookkeeping, as well as for receivable and payable accounts. This enterprise has customers that vary in size, from large cargo companies to small and medium-sized enterprises. All of the enterprise's customers have their own ERP systems. This implies that the enterprise has to adapt to its customers' ERP systems, in one way or another. Some of the customers require that the cargo enterprise logs in to their system to get information regarding invoicing and transportation specifications. However, most of the customers use e-mails to communicate with the transportation enterprise. The e-mail communication is more or less manual and paper-based within the enterprise and the employees print many documents for storage in cover systems 
in bookshelves at the office. Moreover, the drivers manually report their transportation assignments internally. Paper-based reports are handed in by the drivers and this manual process needs to continue, as there are no alternatives.

\subsection{Technical Challenges}

The recruitment agency enterprise has a strong intention to implement an enterprisewide ERP system. The different systems that the company uses today are not integrated to each other. These systems should not continue to be used, as the new ERP system should replace them all. Therefore, no integration is needed between the systems in use and the new ERP system that is planned to be implemented. The goal is to conduct the implementation effectively. It is usual to get technical problems when an ERP system is integrated with existent systems, but that is obviously not the case in this enterprise.

The software developing enterprise has a lot of technical knowledge and competence. However, this knowledge and competence is used to develop the specific software and is therefore a scarce resource in the enterprise. The management is fully aware of this situation and hesitates to implement an ERP system, even though there is a need to make the internal processes more efficient and a CRM system is needed. It is of utmost importance to establish good contact with an ERP systems vendor and have one person as a contact person who can give quick and reliable support to the employees of the software developing enterprise, when needed. The chosen ERP should support the processes in the enterprise in an effective and efficient way. The enterprise emphasized that the system should be up to date with the latest user interface and technology. The system should not come with additional tasks and should therefore be quite automated. The system should also be easy to use. If it is too complicated, it will not be used.

The manager of the cargo enterprise has little knowledge and competence in technical aspects of ERP systems. Thus, this enterprise needs a consultant to manage the implementation process, which the enterprise considers to be very expensive. The manager is worried about the costs that can come with an ERP implementation. The manager is not convinced that an ERP system would make the enterprise more efficient and effective. The administration of transportation is conducted manually today, via SMS from the customers to the drivers or to the manager. The drivers then manually fill in forms that are handed over to the administrator each month and this information is used to calculate the salaries paid to the drivers. The drivers have different nationalities and alternate between driving some weeks and spending some weeks in their home countries. Implementing an ERP systems is not seen as a necessity from the manager's perspective, as he has implemented smooth manual processes a long time ago.

\subsection{Projects' Performance}

Implementing a new ERP system at the recruitment agency should not cause large organizational changes, as only five employees work at the company. The consultants will of course be affected. However, the consultants organize their own work and have to comply with the customers and their work processes. As the enterprise's existing systems are manual and therefore inefficient, implementation of a new ERP systems should facilitate the work, as all the information will be collected in one place and can be accessed within one system. Thus, the company values an integrated ERP system. The enterprise is aware that they should analyze work tasks, activities and processes performed, in order to align their work to the ERP system that they want to implement.

The manager of the recruitment enterprise is well aware of the need to engage all the employees in the implementation process. All the employees also understand the need for a more efficient system. Support from the management is one of the most critical success factors when implementing an ERP system in a small enterprise. Together with the ERP system supplier, the recruitment enterprise has created a requirements specification. The specification includes all the requirements and prerequisites for the implementation of the ERP system. This document is a guide when planning the project. The most important 
part would be to take the requirements that "should" be met into account. Thereafter, the eligible and desirable requirements should be prioritized. The enterprise wishes to stop using Google Drive and would like to have a better overview of their consultants and their customers. They would prefer to have all information in only one system, in order to avoid using more than one software. The requirements specification will constitute an agreement between the supplier of an ERP system and the company. It is important that all the involved parties are aware of how the implementation project should be performed.

The software developing enterprise anticipates that a new ERP system would transform much of their work and that the work processes could become more efficient. It is of great value that the manager of the enterprise will be very engaged in the implementation process. In this enterprise, it is the manager who develops the work and sets the goals. However, the manager has good support from the enterprise's steering group, but it is the manager who points out the future direction of the enterprise. If the manager decides to implement an ERP system, he will create conditions so that the employees can start to use the system and lack of support from the manager will not hinder the implementation. If the ERP system is adapted to the business in the enterprise, it will be introduced shortly.

The cargo enterprise is not so convinced that an investment in an ERP system is of great value. The enterprise's suppliers and customers use different ERP systems and there is a huge fear of large integration problems. Thus, there is also significant concern that the ERP system with all the integration needs will cost too much and that it will be too cumbersome to use thereafter. The manager is very involved in the operative business and does not have much time to familiarize himself with processes that can be digitized in the company. Unfortunately, none of the employees have time to lead the implementation process either, as they are occupied with other work tasks within the enterprise. In this case, a consultant has to be engaged in the implementation process and this will also incur large costs for the enterprise. In this situation, there is a risk that the work processes will continue as previously and it can be expected that the new ERP system will have a low degree of use after implementation.

\subsection{The Importance of Training}

The recruitment agency enterprise will provide an introductory demonstration of the ERP system in the implementation process. After that, the employees are expected to be quite able to learn the functions by themselves. It is also expected that the employees will use the ERP system after it is implemented, as all the employees need to have access to the very same information.

In the software developing enterprise, the vendor of the ERP system will give the employees an introductory education. The manager will then arrange for a meeting where all the employees will go through the overall functions at the same time. After that, new employees will be introduced when they are employed. After this introduction, the employees are supposed to learn by themselves and introduce themselves to the functions in the ERP system that they need. However, the manager is aware that there are many functions in the ERP system that will probably not be used. The manager thinks that they will just scratch the surface when it comes to all the features included in the system. Some of the functions will not fill a need for the enterprise, while other features could certainly be useful and improve processes in the enterprise. Even if the manager is aware of this situation, there is no clear solution to it.

The cargo enterprise expects difficulties in learning a new ERP system, if it is implemented. The employees who are concerned about the ERP system will get an introduction in the office. However, the employees use different manual systems and their work processes do not need to be so coordinated for performing the work. Even if the work processes could be more efficient with an ERP system, it is uncertain whether all employees will use it. As the manager is not so inclined to learn a new ERP system, the implementation cannot be expected to be successful. 


\section{Discussion}

It is important to analyze the existing activities and processes in an enterprise in order to create a suitable organizational change $[18,24]$. Each organization has its own need of operative changes, systems changes and adaptions, to function in an efficient and effective way [24]. Different enterprises have different prerequisites when implementing an ERP system.

A new ERP system should facilitate the operation processes for the enterprise, as the system will be handling the information enterprise-wide [18]. However, even if the implementation is a costly process and a large investment for a small enterprise, an ERP system is intended to support the company to gain competitive advantage [8]. This is also in line with Poba-Nzauo and Raymond [39], as one of their claims is that SMEs do not perceive ERP systems simply as technological tools, but rather as strategic systems that can help enterprises achieve their goals. Training is an important part of the implementation process, as lack of education and training often lead to negative attitudes and unsuccessful implementation [25]. However, successful implementation does not only depend on the quality and quantity of training, as the results from the presented cases have shown.

The goal of the implementation is to perform it in an effective way. However, it is hard to anticipate which problems can occur [18]. Nevertheless, it is important that the ERP system's vendor controls the implementation process and that there is an effective project management team [26]. Moreover, it is important that the small enterprise is aware that implementing an ERP system requires time, costs and engagement and that the success is dependent on the environment in the enterprise. As the implementation affects all employees in an organization, it is important that not only the management has the responsibility for the project [25]. According to Phelan [30], the employees have to accept the changes, to avoid resistance and also assure that there are no negative impacts on the daily work. It is also important that someone at the enterprise is responsible, if not the manager and that this person has been authorized to perform in this role. Otherwise, the risk for an unsuccessful implementation is imminent. The implementation of ERP systems in SMEs is thus challenged by issues involving people. This can be compared to the study by Haaland and Olsen [40], which demonstrates that challenges are related to people issues, rather than technical issues.

Implementation projects are risky and can have negative consequences. According to Raj and Seetharaman [27], it is important to create good prerequisites for project planning, as deficits in planning can imply large risks. Inadequate project planning can have large consequences, as the timetable can be delayed. Moreover, a well performed project management will create good communication between the supplier and the company as a customer and good interactions [25]. The quality of the project team is of great importance, which is also supported by Chatti, Radouche and Asfoura [41].

\section{Conclusions}

The aim of implementing ERP systems is to make companies' business processes more effective and efficient, in order to gain competitive success on the market. However, some risk factors are prevalent for small companies that plan to implement ERP systems. It is important to analyze the existing routines and performance of the activities and processes in the company to create processes that could be implemented in a new ERP system. Although an ERP system is a good solution to avoid using more than one system in parallel, systems that are not integrated, it could require much work to integrate information from other ERP systems used by an enterprise's suppliers and customers. An ERP system should collect all information in only one system and all information should also easily be accessible within that system, otherwise it will not contribute to better efficiency in the small enterprise. The implementation should therefore lead to decreasing costs in the daily work as the activities and processes can be performed in more effective and efficient ways. The engagement in the implementation is of great importance. If the manager or another 
responsible employee is not engaged in the implementation process, there is a risk that the implementation of the ERP system will be unsuccessful.

For further research, it is recommended to study cases where ERP implementations were unsuccessful and where they were successful and compare how the risks were taken into account. To study the risks related to inter-organizational collaboration between enterprises when implementation of ERP system is planned, is also an important area for further research.

Author Contributions: Conceptualization, A.S. and A.T.; methodology, A.S. and A.T.; data collection; A.S. and A.T.; formal analysis, A.S. and A.T.; writing-original draft preparation, A.S. and A.T.; writing-review and editing, A.S.; project administration, A.S.; funding acquisition, A.S. All authors have read and agreed to the published version of the manuscript.

Funding: This research partially received external funding from Interreg Sweden-Norway, European Regional Development Fund (ERDF), by the project Framgångsrika företag i gränsregionen (FRAMFOR), grant number: 20200960.

Institutional Review Board Statement: Not applicable.

Informed Consent Statement: Informed consent was obtained from all subjects involved in the study.

Data Availability Statement: The data presented in this study are available on request from the corresponding author. The data are not publicly available due to privacy restrictions.

Acknowledgments: The authors would like to express our sincerest gratitude to all the participants for their cooperation during the process of data collection.

Conflicts of Interest: The authors declare no conflict of interest.

\section{References}

1. Eseryel, U.Y.; Eseryel, D.; Wolters, J. Managing Successful Information Systems Implementations at Small and Medium Enterprises Managerial IS Implementation Effectiveness Theory. J. Leadersh. Manag. 2020, 1. Available online: https: //www.researchgate.net/profile/U-Eseryel/publication/348363566_Managing_Successful_Information_Systems_Implemen tations_at_Small_and_Medium_Enterprises_Managerial_IS_Implementation_Effectiveness_Theory/links/5ffa7dd692851c13fe ffcc72/Managing-Successful-Information-Systems-Implementations-at-Small-and-Medium-Enterprises-Managerial-IS-Impl ementation-Effectiveness-Theory.pdf (accessed on 14 November 2021).

2. Goldston, J.A. Qualitative Study of Risk Mitigation in Enterprise Resource Planning Implementations. Glob. Sci. J. 2019, 7, 1129-1159.

3. Xu, H.; Rondeau, P.J.; Mahenthiran, S. Teaching Case the Challenge of Implementing an ERP System in a Small and Medium Enterprise-A Teaching Case of ERP Project Management. J. Inf. Syst. Educ. 2011, 22, 291-296.

4. Ravasan, A.Z.; Mansouri, T. A dynamic ERP critical failure factors modelling with FCM throughout project lifecycle phases. Prod. Plan. Control. 2015, 27, 65-82. [CrossRef]

5. Sudhaman, P.; Thangavel, C. Efficiency analysis of ERP projects—software quality perspective. Int. J. Proj. Manag. 2015, 33, 961-970. [CrossRef]

6. Lundberg, D. Konsten att Lyckas Med Investeringar i IT; Studentlitteratur: Lund, Sweden, 2014.

7. Amba, S.M.; Abdulla, H. The impact of enterprise systems on small and medium-sized enterprises in the kingdom of Bahrain. Int. J. Manag. Mark. Res. 2014, 7, 49-57.

8. Malhotra, R.; Temponi, C. Critical Decisions for ERP Integration: Small Business Issues. Int. J. Inf. Manag. 2010, 30, 28-37. [CrossRef]

9. Bansal, V.; Agarwal, A. Enterprise resource planning: Identifying relationships among critical success factors. Bus. Process. Manag. J. 2015, 21, 1337-1352. [CrossRef]

10. Kiran, T.S.; Reddy, A.V.D. Evaluating critical success factors of ERP implementation in SMEs. Int. J. Recent Technol. Eng. 2019, 8, 1144-1149.

11. Johansson, A.; Svensson, A. Identifying risk factors in implementing ERP systems in small companies. In Proceedings of the Information Technology: New Generations (ITNG 2020), Las Vegas, NV, USA, 5-8 April 2020; Springer: Berlin/Heidelberg, Germany.

12. Venkatraman, S.; Fahd, K. Challenges and success factors of ERP systems in Australian SMEs. Systems 2016, 4, 20. [CrossRef]

13. Vayyavur, R. ERP implementation challenges \& critical organizational success factors. Int. J. Curr. Eng. Technol. 2015, 5, $2347-5161$.

14. Alshawi, S.; Themistocleus, M.; Almadani, R. Integrating Diverse ERP Systems: A Case Study. J. Enterp. Inf. Manag. 2004, 17, 454-462. [CrossRef] 
15. Garg, P.; Garg, A. An empirical study on critical failure factors for enterprise resource planning implementation in Indian retail sector. Bus. Process. Manag. J. 2013, 19, 496-514. [CrossRef]

16. Taghipour, M.; Shabrang, M.; Habibi, M.H.; Shamami, N. Assessment and Analysis of Risk Associated with the Implementation of Enterprise Resource Planning (ERP) Project Using FMEA Technique (Including Case-Study). Management 2020, 3, $29-46$.

17. Haddara, M.; Zach, O. ERP Systems in SMEs: A Literature Review. In Proceedings of the 44th Hawaii International Conference on Systems Sciences, Kauai, HI, USA, 4-7 January 2011.

18. Magnusson, J.; Olsson, B. Affärssystem; Studentlitteratur: Lund, Sweden, 2008.

19. Munkelt, T.; Völker, S. ERP Systems: Aspects of Selection, Implementation and Sustainable Operations. Int. J. Inf. Syst. Proj. Manag. 2013, 1, 25-39.

20. Gupta, S.; Misra, S.C.; Kock, N.; Roubaud, D. Organizational, technological and extrinsic factors in the implementation of cloud ERP in SMEs. J. Organ. Chang. Manag. 2018, 31, 83-102. [CrossRef]

21. Kumar, V.; Maheshwari, B.; Kumar, U. An investigation of critical management issues in ERP implementation: Emperical evidence from Canadian organizations. Technovation 2003, 23, 793-807. [CrossRef]

22. Menon, S. Critical challenges in enterprise resource planning (ERP) implementation. Int. J. Bus. Manag. 2019, 14, 7. [CrossRef]

23. Fredholm, P. Logistik E IT: För Effektivare Varuflöden; Studentlitteratur: Lund, Sweden, 2013.

24. Sullivan, L. Post-Implementation Success Factors for Enterprise Resource Planning (ERP) Student Administration Systems in Higher Education Institutions; Department of Education Research, Technology, and Leadership in the College of Education at the University of Central Florida: Orlando, FL, USA, 2009; pp. 20-45.

25. Ganly, D. Address Six Key Factors for Successful ERP Implementations. Gart. Res. 2011, ID Number: G00206726. Available online: https:/ / www.gartner.com/en/documents/1603415/address-six-key-factors-for-successful-erp-implementatio (accessed on 14 November 2021).

26. Finney, S.; Corbett, M. ERP Implementation: A Compilation and Analysis of Critical Success Factors. Bus. Process. Manag. J. 2007, 13, 329-344. [CrossRef]

27. Raj, J.R.; Seetharaman, A. Business Issues in Enterprise Resource Planning (ERP) Implementation. East Asian J. Bus. Econ. 2014, 2, 9-25.

28. Somers, T.M.; Nelson, K. The impact of critical success factors across the stages of enterprise resource planning implementations. In Proceedings of the 34th Annual Hawaii International Conference on System Sciences, IEEE, Maui, HI, USA, 6 January 2001; p. 10.

29. Hanif, M.; Khan, Y.S.; Zaheer, A. Impact of Organizational Resistance to Change on BPR Implementation: A Case of State Bank of Pakistan. Eur. J. Bus. Manag. 2014, 6, 186-196.

30. Phelan, P. ERP Upgrades: Quality Assurance is About More Than Application Testing. Gart. Res. 2010, ID Number: G00205670.

31. Merriam, S.B. Fallstudien Som Forskningsmetod; Studentlitteratur: Lund, Sweden, 1994.

32. Yin, R.K. Case Study Research: Design and Methods; Sage Publication Inc.: London, UK, 2014.

33. Klein, H.K.; Myers, M.D. A set of principles for conducting and evaluating interpretive field studies in information systems. MIS Q. 1999, 23, 67-93. Available online: https://www.jstor.org/stable/249410 (accessed on 14 November 2021). [CrossRef]

34. Flyvbjerg, B. Five misunderstandings about case-study research. Qual. Inq. 2006, 12, 219-245. [CrossRef]

35. Gioia, D.; Corley, K.; Hamilton, A. Seeking Qualitative Rigor in Inductive Research: Notes on the Gioia Methodology. Organ. Res. Methods 2012, 16, 15-31. [CrossRef]

36. Myers, M.D. Investigating Information Systems with Ethnographic Research. Commun. AIS 1999, 2, 23. [CrossRef]

37. Repstad, P. Närhet och Distans; Studentlitteratur: Lund, Sweden, 1999.

38. Braun, V.; Clarke, V. Using thematic analysis in psychology. Qual. Res. Psychol. 2006, 3, 77-101. [CrossRef]

39. Poba-Nzaou, P.; Raymond, L. Managing ERP system risk in SMEs: A multiple case study. J. Inf. Technol. 2011, 26, 170-192. [CrossRef]

40. Haaland, E.; Olsen, O.A. Managing Change in ERP Implementation Projects: A Case Study in an SME Context; University of Agder: Kristiansand, Norway, 2020.

41. Chatti, H.; Radouche, T.; Asfoura, E. Framework for the evaluation of the ERP implementation syccess: Case study in SMEs. J. Manag. Inf. Decis. Sci. 2021, 24, 1-25. 